\title{
Home range use in the West Australian seahorse Hippocampus subelongatus is influenced by sex and partner's home range but not by body size or paired status
}

\author{
Charlotta Kvarnemo $^{1}$ (D) S Susanne E. Andersson ${ }^{1} \cdot$ Jonas Elisson $^{1} \cdot$ Glenn I. Moore $^{2,3}$ (D) $\cdot$ Adam G. Jones $^{4}$ (D)
}

Received: 11 December 2020 / Accepted: 23 March 2021 / Published online: 3 April 2021

(c) The Author(s) 2021

\begin{abstract}
Genetic monogamy is the rule for many species of seahorse, including the West Australian seahorse Hippocampus subelongatus. In this paper, we revisit mark-recapture and genetic data of $H$. subelongatus, allowing a detailed characterization of movement distances, home range sizes and home range overlaps for each individual of known sex, paired status (paired or unpaired) and body size. As predicted, we find that females have larger home ranges and move greater distances compared to males. We also confirm our prediction that the home ranges of pair-bonded individuals (members of a pair known to reproduce together) overlap more on average than home ranges of randomly chosen individuals of the opposite or same sex. Both sexes, regardless of paired status, had home ranges that overlapped with, on average, 6-10 opposite-sex individuals. The average overlap area among female home ranges was significantly larger than the overlap among male home ranges, probably reflecting females having larger home ranges combined with a female biased adult sex ratio. Despite a prediction that unpaired individuals would need to move around to find a mate, we find no evidence that unpaired members of either sex moved more than paired individuals of the same sex. We also find no effect of body size on home range size, distance moved or number of other individuals with which a home range overlapped. These patterns of movement and overlap in home ranges among individuals of both sexes suggest that low mate availability is not a likely explanation for the maintenance of monogamy in the West Australian seahorse.
\end{abstract}

Keywords Mark-recapture $\cdot$ Mating system $\cdot$ Mating status $\cdot$ Monogamy $\cdot$ Pair bond $\cdot$ Syngnathidae

\section{Introduction}

Space use is often related to an animal's mating system (Emlen and Oring 1977; Hixon 1987; Clutton-Brock 1989). Other factors that determine space use, including the size of an individual's home range, are energy requirements,

Charlotta Kvarnemo

lotta.kvarnemo@bioenv.gu.se

1 Department of Biological and Environmental Sciences, University of Gothenburg, Box 463, 40530 Gothenburg, SE, Sweden

2 Collections and Research, Western Australian Museum, Welshpool, WA, Australia

3 School of Biological Sciences, University of Western Australia, Perth, WA, Australia

4 Department of Biological Sciences, University of Idaho, Moscow, ID, USA locomotion strategy, trophic guild and prey size (Kelt and Van Vuren 1999; Tamburello et al. 2015), all of which can differ between the sexes (e.g. Vincent et al. 2005; Foley et al. 2015). Sex differences in movement patterns can thus arise from ecological differences between the sexes or from differing reproductive interests. The relationship between mating systems and space use is especially interesting, as the causal arrow can point either direction. For instance, males of a polygynous species might be motivated to move large distances to find additional suitable mates, resulting in greater space use by males (Brown and Weatherhead 1999; Radespiel 2000). Alternatively, males with large home ranges for feeding purposes or other ecological reasons could be polygynous merely because their territories overlap with the home ranges of multiple females (Hixon 1987).

A mating system of particular interest is monogamy, which appears to represent a scenario favoring similar patterns of space use by members of both sexes. While molecular methods show that many socially monogamous species 
are genetically polygamous, i.e. they reproduce with more than one partner (Avise 1996; DeWoody and Avise 2001; Griffith et al. 2002), the same methods also demonstrate that strict genetic monogamy does occur in a wide range of taxa (Kvarnemo 2018), including birds (e.g. Piper et al. 1997; Marks et al. 1999; Robertson et al. 2001; Kleven et al. 2008; Rodriguez-Martínez et al. 2014), mammals (Ribble 1991; Brotherton et al. 1997; Hohoff et al. 2002; Huck et al. 2014; Syrůčková et al. 2015) and fish (DeWoody et al. 2000; Egger et al. 2006; Tatarenkov et al. 2006; Schaedelin et al. 2015; Woodall et al. 2011; Rose et al. 2014). The underlying reasons for individuals to form pair-bonds and be reproductively faithful to each other over time are diverse (Kvarnemo 2018).

A fish species exhibiting a high degree of genetic monogamy is the West Australian seahorse Hippocampus subelongatus (previously synonymized with Hippocampus angustus) (Jones et al. 1998, 2003; Kvarnemo et al. 2000, 2007). Hippocampus subelongatus belongs to the family Syngnathidae, consisting of seadragons, pipefishes and seahorses (Herald 1959; Lourie et al. 1999). Within Syngnathidae, the male cares for the offspring by carrying the eggs during development (Wilson et al. 2001; Stölting and Wilson 2007; Whittington and Friesen 2020). Previous studies show that $H$. subelongatus males receive eggs from only one female in each brood (Jones et al. 1998), that males and females mate size-assortatively (Jones et al. 2003), and that they can form lasting pair-bonds, re-mating with the same partner over two or more broods within a season, although they also sometimes change partners between broods (Kvarnemo et al. 2000, 2007).

This pattern of monogamy within and sometimes also between broods has been found in several species of seahorses, despite ample opportunities for promiscuity in some populations (Vincent et al. 2004; Wilson and Martin-Smith 2007). The pot-bellied seahorse Hippocampus abdominalis, for example, shows behavioral promiscuity, with 1 male and 3-6 females displaying together, yet all sampled males carried eggs from a single female only (Wilson and MartinSmith 2007). In H. subelongatus, males mating with the same female in two consecutive broods move less and tend to have shorter inter-birth intervals, compared to males that switch mates between broods, indicating important benefits to lasting pair-bonds (Kvarnemo et al. 2000). Similar results have been found in Hippocampus fuscus (Vincent 1994) and Hippocampus zosterae (Masonjones and Lewis 2000). In the $H$. subelongatus study population, the adult sex ratio was approximately 1.4 females per male (Kvarnemo et al. 2007). This skewed sex ratio generates strong sexual selection on females, with many females failing to find a mate, and larger females being more successful (Kvarnemo et al. 2007).

In Hippocampus breviceps, H. guttulatus and H. subelongatus the areas where individuals reside often overlap with many other individuals of the same and opposite sex (Moreau and Vincent 2004; Curtis and Vincent 2006; current study), suggesting these areas are undefended home ranges rather than defended territories. For syngnathids, it has been argued that since they are ambush hunters, attacking prey that swim past, they do not need to move specifically to find food, which may explain their relatively small home ranges (Vincent et al. 2005). In general, the size and location of a seahorse home range is likely to be determined by the availability of habitats that provide opportunities for reproduction, survival and growth (Vincent et al. 2005). Still, as explained below, sex, paired status and body size may all affect home range use. That is the focus of this paper.

In many taxa, female reproductive rate is often more dependent on food intake than is male reproductive rate (e.g. Kvarnemo 1997; Miller and Svensson 2014; Janicke et al. 2015) as females rely heavily on ingesting enough food to produce a new set of mature eggs in time for the next breeding cycle. Similarly, females of several pipefish species eat more and larger prey than males (e.g. Svensson 1988; Steffe et al. 1989; Teixeira and Musick 1995; Lyons and Dunne 2004; Garcia et al. 2005; Kitsos et al. 2008; Manning et al. 2019). Assuming that $H$. subelongatus females also need more food and that a large home range provides access to more food, we predict females to have larger home range sizes than males.

Several species of seahorses, including $H$. subelongatus, are known to have long-term relationships over several brood cycles (Vincent and Sadler 1995; Kvarnemo et al. 2000, 2007), form pair-bonds size assortatively (Jones et al. 2003) and be reproductively monogamous within and sometimes also between broods (Jones et al. 1998; Kvarnemo et al. 2000, 2007; Wilson and Martin-Smith 2007). There may be few reasons for already paired individuals to look for a new partner, whereas unpaired individuals should make themselves available, for example through mate search. We thus predict unpaired individuals to move around more in search of mates, and the home ranges of unpaired individuals to overlap more (in extent and number of individuals) with opposite sex individuals. In addition, in order for pairs to stay in contact, we predict the home ranges of males and females known to reproduce together, to overlap to a greater extent than home ranges of randomly chosen individuals of the opposite or same sex. We use home range overlap to infer the likelihood that two individuals have an opportunity to meet one another.

Body size may also affect home range use, for three reasons. (i) In the pipefish Syngnathus typhle smaller adults of both sexes were more interested in food and less in mates compared to larger individuals (Berglund et al. 2006). If the same is true for $H$. subelongatus and if home range size is mainly driven by foraging needs, we predict smaller individuals of both sexes to have larger 
home ranges. (ii) Previous work has shown that large $H$. subelongatus females (but not males) have higher mating success than small females (Kvarnemo et al. 2007). Since large females are therefore more likely to be paired, they should have less need to move around in search of a mate compared to smaller females. Hence, we predict especially large paired female $H$. subelongatus to have smaller home ranges than smaller females, if home range size is mainly driven by mate searching. (iii) On the other hand, if home range size is an expression of dominance or mating competition among females, we predict large paired females to have larger home ranges than smaller paired or unpaired females.

Low mate availability can make it advantageous to stay with a current partner than to try to find a new one (Barlow 1984; Whiteman and Côté 2004; Kokko and Rankin 2006). Low mobility and small home ranges may reduce mate availability, a situation that correlates with reproductive monogamy in some taxa (e.g. seamoths; Herold and Clark 1993). If this is also true in the sequentially monogamous $H$. subelongatus, we predict their home ranges to overlap with very few individuals of the opposite sex. Thus, again, we use home range overlap to infer the likelihood that two individuals have a chance to encounter each other.

\section{Aims}

Studying a wild population of tagged West Australian seahorses Hippocampus subelongatus, of known paired status and body size, we aimed to test the predictions listed above regarding home range use in relation to sex (male or female), paired status (paired or unpaired) and body size, and if home ranges of known pairs overlap to a greater extent than expected by chance. To do so, we focused on the following specific questions:

1. Is there a difference in home range size and distance moved between paired and unpaired males and females?

2. Home range overlap measured as number of individuals: Do the home ranges of unpaired males or females overlap with a larger number of opposite sex individuals than paired individuals do?

3. Home range overlap measured as area: Do the home ranges of pair-bonded individuals that reproduce together overlap more with one another than with other opposite sex individuals and do male-male and femalefemale overlaps differ in extent?

4. Does body size affect home range size or distance moved?

5. Is low mate availability a likely explanation for sequential monogamy in the study population?

\section{Methods}

Spatial and statistical analyses were performed on previously published data (Jones et al. 2003; Kvarnemo et al. 2007) regarding the genetic mating system and movement patterns of the West Australian seahorse Hippocampus subelongatus.

\section{Previous study}

The study was carried out from the end of January through March 1999 over a total period of 47 days at a site south of Perth in Western Australia. This time period represents the second half of the breeding season, which usually lasts from early December to late March. The total number of adult individuals was 103 , of which 43 were males and 60 were females. Thus, the study population showed a female-biased adult sex ratio. The study area was approx. $100 \mathrm{~m} \times 25 \mathrm{~m}$ (incorrectly reported as $100 \mathrm{~m} \times 65 \mathrm{~m}$ in Kvarnemo et al. 2007) and included 25 pylons of a jetty at $3-5 \mathrm{~m}$ depth as well as 82 short stumps (0.1-2 m high) from an older demolished jetty at $8-10 \mathrm{~m}$ depth (Fig. 1a). The site was mapped using compass and tape measure and all stumps and pylons were labelled with numbers. This is the same area that was studied in 1998 (Kvarnemo et al. 2000), but included three additional pylons at the western end of the jetty, at approx. $3 \mathrm{~m}$ depth, and an additional section of very short stumps at the western end of the demolished jetty. The seahorses were monitored by SCUBA diving 2-5 days per week for a total of 22 dive days. All dives were undertaken within the time range $9 \mathrm{am}-2 \mathrm{pm}$ and most observations of location were made on our first dive for the day, always before noon. All dives started by first surveying the southern row of stump-pairs (Fig. 1a), heading east until the end of the row, then turning around and following the northern row, heading west. The two divers inspected one stump each in a pair in synchrony (with our heads down and fins up, to get the best view and avoid stirring up mud from the soft bottom). Any untagged individuals that were found were collected in labelled containers, held in a catch bag, and tagged individuals were noted (position and pregnancy status for males), before moving on to the next pair of stumps. We then surveyed the jetty by swimming around each pylon to a height of approximately $2 \mathrm{~m}$ above the seafloor. A full survey took 45-60 min. Following the protocol described in more detail in Kvarnemo et al. (2000, 2007), the untagged individuals were briefly brought to the jetty for measuring, tagging and fin clipping, and pregnant males for brood sampling, after which they were promptly returned to the position where they were found. Only the first sighting of each animal was included in our data for each day. 
a

N

\section{Demolished jetty}
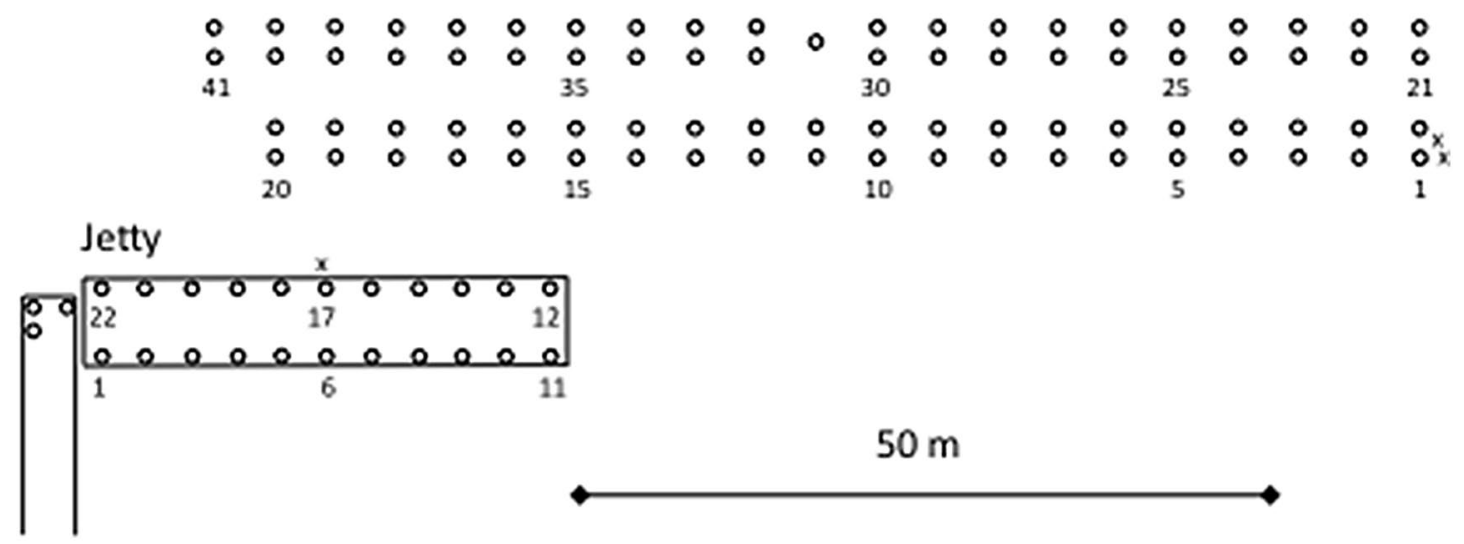

b

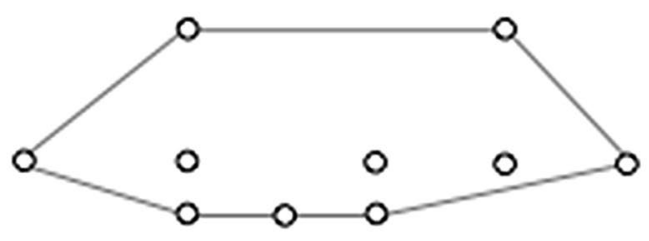

C

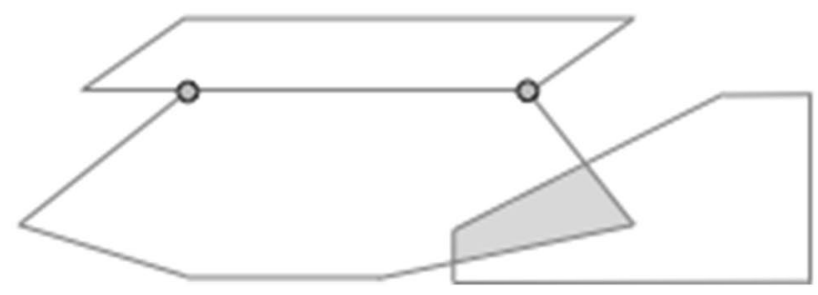

Fig. 1 a Map of the study area with a jetty at 3-5 m depth and remaining stumps from an older demolished jetty at 8-10 $\mathrm{m}$ depth. The pylons and stumps (indicated by open circles) of the two jetties create an underwater grid that was used to record positions of tagged seahorse (Hippocampus subelongatus) individuals on each dive. The positions marked with an $\mathrm{x}$ indicate additional sites used by seahorses (a chair, a stick and a tyre). b The graph illustrates how home range

Auto-correlation among data collected for an individual can be a problem, especially when position data are collected very frequently e.g. by radio-tracking (Harris et al. 1990). In our case, however, the risk of auto-correlation was reduced as all sequential observations were collected $\geq 1$ day apart. Also, pair-bonded H. whitei are known to greet each other early in the morning at a specific location, but spend the rest of the day apart (Vincent area was estimated, using the minimum convex polygon method, for an individual seen at ten different positions (open circles). c The graph illustrates how the area of home range overlap between two individuals was calculated (shaded grey area). The graph also illustrates a case where the home ranges of two individuals did not overlap, but they shared two positions along a common line (grey circles). Each shared position was counted as a $0.5 \mathrm{~m}^{2}$ overlap

and Sadler 1995). We expect that H.subelongatus shows the same pattern, since courtship behaviours are almost exclusively observed in the early morning (G. I. M. personal observation), so the late morning timing of our dives should reduce the risk of repeated observations at the greeting spot. 


\section{Determination of paired status and pair-bonds}

Microsatellite DNA genotyping of the broods and adult fin clips allowed female genotypes to be matched to broods, from which mated pairs and pair-bonds were inferred. Since it is known from previous work that a male only carries offspring from one female at a time (Jones et al. 1998; Kvarnemo et al. 2000), a small sample (approx. 20 embryos per brood, representing $<5 \%$ of the whole brood) was enough to identify the female with which a male had mated, and the rest of the brood continued to develop as normal. The brood sampling procedure is described elsewhere (Kvarnemo et al. 2000, 2007).

Male paired status was determined based on whether males were seen pregnant or not, as judged from the shape of their brood pouches. However, we were not able to tell if females were carrying mature eggs or were newly mated based on the shape of their abdomen. Instead, our estimates of female paired status depended solely on whether we found a match of a female's genotype in one of the sampled broods. Some of the females that were categorized as unpaired could have mated with one of eleven pregnant males for which we failed to obtain a brood sample that could be genotyped. These females could also have mated with a male that was not found, not seen pregnant or that resided outside our study area.

\section{New analysis of data}

\section{Exclusion of data}

The number of sightings (i.e. how many times an individual was seen over the study period) varied between 1 and 17 times. For both sexes, individuals categorized as 'paired' had been seen a greater number of times than 'unpaired' individuals (ANOVA: sex: $\mathrm{F}_{1,99}=1.24, p=0.27$; paired status: $\mathrm{F}_{1,99}=12.3, p=0.001$; interaction: $\mathrm{F}_{1,99}=2.14, p=0.15$ ). This might mean that individuals that remained in the area were more likely to breed there, but it also suggests that a greater number of observations improved our estimate of paired status. To reduce this source of error, and to remove the problem that distance moved between sightings could not be estimated for individuals with a single observation, we excluded all 12 individuals that were only seen once from our analyses. The excluded individuals were 4 unpaired and 1 paired male, 4 unpaired and 3 paired females. In addition, 1 female was excluded from the data set, because she was never fin clipped, hence preventing us from genotyping her, a crucial step to assess her paired status. This individual was also excluded in Kvarnemo et al. (2007). The remaining 90 individuals were included in the analyses, of which 32 were unpaired females, 20 paired females, 5 unpaired males and 33 paired males. Including all individuals seen once does not affect any of our conclusions from the statistical analyses, but it does reduce the mean values for home range area and number of overlaps (total, with females and with males). Similarly, running the analyses excluding all individuals seen less than five times does not affect any of the conclusions.

\section{Size of home range}

We used the Minimum Convex Polygon method to estimate home range areas. This method focuses on where one knows for sure that an individual has been (Harris et al. 1990). The method creates a polygon that covers all points where the outermost positions are the boundary and where the inner angles do not exceed 180 degrees (Worton 1987), similar to pulling a rubberband around pins, for which each position an individual has been seen is a pin. Although the method has some disadvantages, it has many advantages, especially when the numbers of re-sightings are low (Harris et al. 1990; Seaman et al. 1999; Boyle et al. 2009), as is the case in this study. We also favored this measure over other alternatives, as it is a well-established method that is often used in the seahorse literature, thus facilitating comparisons between species or meta-analyses in the future.

We digitized the existing raw data of position and reproductive status of tagged individuals collected over the study period and assigned coordinates to all mapped positions. The 100\% Minimum Convex Polygon (MCP) method was used (Fig. 1b) in the spatial analysis software Biotas (2.0a) to calculate a home range area for each individual. MCP could not be calculated for all individuals. To avoid having to exclude a larger number of individuals, in addition to the ones that were only seen once, we took the following approach: For individuals that were seen at the same site several times, which would have given them a MCP area of zero, the tool buffer in Biotas was used to create surfaces. The buffer radius was set at $0.4 \mathrm{~m}$ based on the radius of the pylons and stumps plus additional habitat around the pylon, which results in an area of $0.5 \mathrm{~m}^{2}$. Since both pylons and stumps were positioned in straight lines, linear home ranges were relatively common. An individual found along a line received a summed area, that is, the number of positions $\times 0.5 \mathrm{~m}^{2}$. Individuals found at two positions further apart received a buffer of $0.5 \mathrm{~m}^{2}$ even for intermediate positions, since it is likely that the individual also visited intervening pylons. For these individuals, the estimated home range size might be a slight underestimate. In comparison, when the home range area was based on MCP, the open silty areas between stumps and pylons, which were rarely used as habitat by these seahorses except for transit, were included. Hence, for these individuals the effective home range size is probably overestimated (cf. Burt 1943). 


\section{Distance moved}

For each individual, movement distance between subsequent sightings was recorded and linked to sex and paired status. This procedure was repeated for all times an individual was seen, which allowed us to calculate the summed distance moved over all sightings.

\section{Home range overlap}

Pairwise home range overlap was calculated among all 90 individuals. We measured home range overlap both as (i) the number of males and females the focal individual overlapped with and (ii) the area of home range overlaps. To calculate the overlapping area, we used a custom Python program. The code is available on Dryad (https://doi.org/10.5061/dryad. w9ghx3fnz). The program created polygons from the Minimum Convex Polygon method with data derived from each individual (Fig. 1b). All polygons (i.e. home ranges) were compared to each other. If the polygons overlapped, the area of intersection was calculated. If there was no overlap but the polygons touched each other along a line, the number of shared positions was multiplied by $0.5 \mathrm{~m}^{2}$ (Fig. 1c). If the intersection was only one point, $0.5 \mathrm{~m}^{2}$ was assigned as the overlapping area. All overlaps were calculated regardless of when an individual was seen at a certain position.

\section{Statistical methods}

A two-factor ANCOVA in SPSS (version 24) was used to examine whether sex, paired status and number of sightings affected (1) home range area, (2) total distance moved, (3) number of female home ranges that focal individuals overlapped with, and (4) number of male home ranges that focal individuals overlapped with. Sex and paired status were included as fixed factors, whereas the number of sightings was used as a covariate, since the more times an individual was seen, the greater was the home range area, distance moved and number of individuals it overlapped with. This means that any effects due to sex or paired status would be expressed primarily as a significant interaction between the factor(s) and the covariate, rather than as significant main effects. Head length can be used as an estimate of body size (Kvarnemo et al 2007). To test if body size affects any of the measured variables of home range use, we included head length as a second covariate in all ANCOVAs. All non-significant interactions were deleted sequentially, i.e. starting with the four-way interaction, followed by the least significant three-way interaction, and so on. Finally, any non-significant covariates were removed from the models. Levene's test was used to assure all variances were homogeneous. All mean values are given with \pm 1 standard error (SE). The raw data for these tests are available on Dryad (https://doi.org/ 10.5061/dryad.w9ghx3fnz).

We used non-parametric permutation tests to compare the mean area of home range overlap for 22 pairs of males and females, known to reproduce together, to home-range overlaps for male-female pairs chosen at random from the population. Four individuals ( 3 males, 1 female) changed partner during the study period. In one case (M176) the identity of both partners was unknown (thus not part of this data set). In one case (M140) only one of the partners was known (F267), and thus included in this analysis. M204 and F233 had two known partners. For them, only the first mate (F201 and M191, respectively) was included in this analysis. The permutation test was implemented in $\mathrm{R}$, and our test statistic was calculated as the difference between the mean home range overlap of known male-female reproducing pairs and the mean home range overlap of randomly chosen pairs of males and females (with the constraint that the members of these latter pairs were not reproducing together). To generate a null distribution for this test statistic, we randomized the home range overlap values among all male-female pairs and recalculated the test statistic 10,000 times. The observed value of the difference between mean home range overlap for reproducing pairs and mean home range overlap for randomly chosen male-female pairs was then compared to the null distribution to calculate a $p$-value. We performed a similar permutation test to compare mean home range overlap among females to mean home range overlap among males. The $\mathrm{R}$ code and raw data for these tests are available on Dryad (https://doi.org/10.5061/dryad.w9ghx3fnz).

\section{Results}

\section{Size of home range}

The home range area $($ mean $\pm \mathrm{SE})$ was $63.3 \pm 16.2 \mathrm{~m}^{2}$ for unpaired females, $93.5 \pm 20.4 \mathrm{~m}^{2}$ for paired females, $36.3 \pm 40.9 \mathrm{~m}^{2}$ for unpaired males and $36.6 \pm 15.9 \mathrm{~m}^{2}$ for paired males. As expected, there was a strong effect of number of sightings on the home range area (ANCOVA: number of sightings: $\left.\mathrm{F}_{1,85}=13.19, p<0.001\right)$, that is the more times an individual was seen, the greater the home range area estimate would be. In addition, the home range area estimate increased more for females than for males with number of sightings (ANCOVA: sex * number of sightings: $\mathrm{F}_{1,85}=4.24$, $p=0.043$; Fig. 2a). This means that females moved over larger areas than males, and that this was most evident for individuals that were seen many times. There was no significant three-way interaction between sex, paired status and number of sightings on home range area, as would have been expected if paired males had smaller home ranges than other groups (as indicated by previous analysis; Kvarnemo et al. 

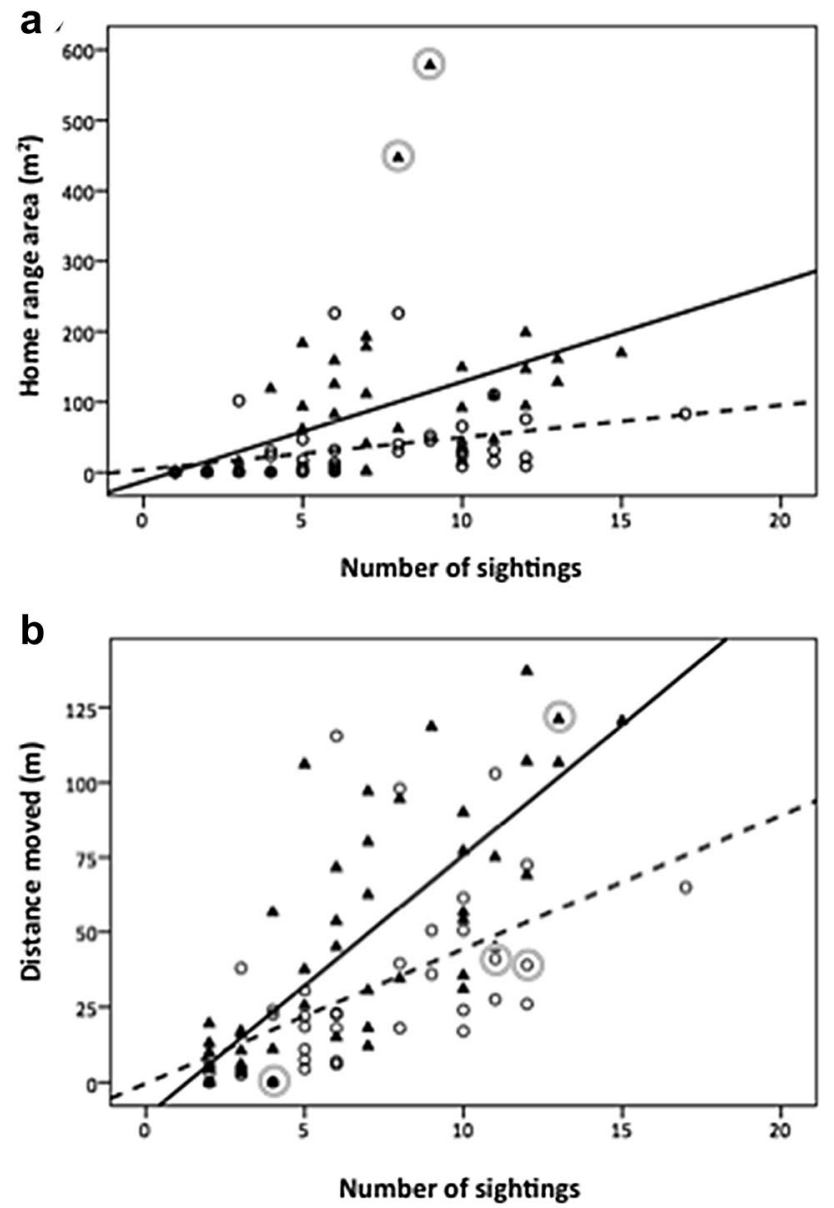

Fig. 2 a Home range area $\left(\mathrm{m}^{2}\right)$ and $\mathbf{b}$ distance moved (m) by seahorse (Hippocampus subelongatus) individuals increased with number of sightings for both sexes, but more so for females than for males, indicating that females have larger home ranges and move longer distances, whereas paired status did not affect the result. Filled triangles and solid lines denote females, open circles and dashed lines males. The results were not affected by excluding encircled data points

2007), or if unpaired females held larger home ranges than other groups as a reflection of mate search. Also, there was no effect of body size, estimated by head length, on home range size, and no interaction with any of the other factors.

As can be seen from Fig. 2a, two females had larger home ranges than others (F173: home range area $578 \mathrm{~m}^{2}, 9$ sightings, head length $39.0 \mathrm{~mm}$; F223: home range area $446 \mathrm{~m}^{2}$, 8 sightings, head length $30.3 \mathrm{~mm}$ ). Removing these females from the analysis does not change the results qualitatively (ANCOVA: number of sightings: $\mathrm{F}_{1,83}=24.91, \mathrm{p}<0.001$; sex $*$ number of sightings: $\mathrm{F}_{1,85}=5.54, \mathrm{p}=0.021$ ).

\section{Distance moved}

On average, individuals moved $6.4 \pm 0.6 \mathrm{~m}$ between two consecutive sightings. The distance moved over the course of our study period was $33.9 \pm 6.3 \mathrm{~m}$ for unpaired females, $56.4 \pm 8.0 \mathrm{~m}$ for paired females, $21.0 \pm 15.9 \mathrm{~m}$ for unpaired males and $32.0 \pm 6.2 \mathrm{~m}$ for paired males. As with area, there was an effect of the number of sightings on the distance moved (ANCOVA: number of sightings: $\mathrm{F}_{1,85}=74.1$, $\mathrm{p}<0.001$ ), i.e. the more times an individual had been sighted, the farther it had moved. The distance increased more for females than for males with the number of sightings (ANCOVA: sex *number of sightings: $\mathrm{F}_{1,85}=8.41$, $p=0.005$; Fig. 2b), meaning that females moved greater distances than males, and this became most evident for the individuals that were seen many times. There was no significant three-way interaction between sex, paired status and the number of sightings with respect to distance moved, and body size had no effect.

In a study at the same site in 1998 (Kvarnemo et al. 2000), focusing on 14 males that were brood sampled at least twice, we found that males who switched mate between sequential broods had moved greater distances between brood sampling occasions, compared to males that re-mated with the same female. To examine if such a polygamous mating pattern may have influenced the distance moved in the current data set, we removed the three males that showed polygyny and the one female that showed polyandry. As indicated in Fig. 2b, these individuals (M204, M175, M140 and F233) were seen 4, 12, 11 and 13 times and moved 0,39, 41 and $121 \mathrm{~m}$, respectively, over the course of the study. However, removing them from the analysis does not change the results qualitatively (ANCOVA: number of sightings: $\mathrm{F}_{1,81}=65.7, p<0.001$; sex $*$ number of sightings: $\mathrm{F}_{1,81}=6.31, p=0.014$ ).

\section{Home range overlaps with number of other individuals (both sexes)}

In general, home range size correlated positively with number of other individuals it overlapped with (Pearson's correlation: $r=0.86, p<0.001, N=90$ ). Both males and females had home ranges that overlapped with the home ranges of many other individuals (unpaired females overlapped with $15.9 \pm 9.8$ individuals; paired females overlapped with $20.0 \pm 12.4$ individuals; unpaired males with $16.4 \pm 5.3$ individuals; paired males with $15.8 \pm 6.7$ individuals).

\section{Home range overlaps with females}

Unpaired females overlapped with $9.8 \pm 0.9$ females, paired females with $11.1 \pm 1.1$ females, unpaired males overlapped with $10.0 \pm 2.3$ females and paired males with $9.8 \pm 0.9$ females. Paired status and sex of individuals did not affect how many female home ranges they overlapped with (ANCOVA: sex: $\mathrm{F}_{1,86}=0.35, p=0.56$; paired status: $\left.\mathrm{F}_{1,86}=0.002, p=0.96\right)$. There was an effect of the 

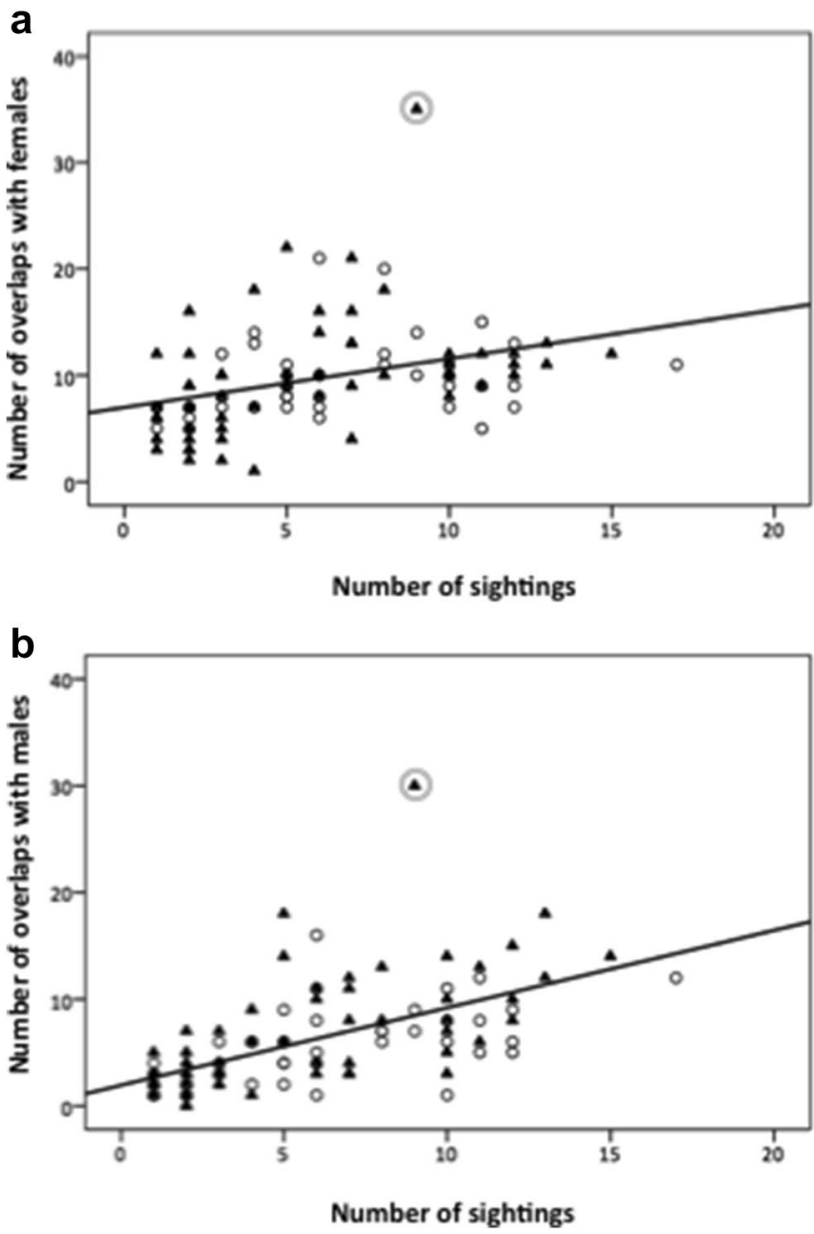

Fig. 3 In Hippocampus subelongatus, individuals' number of overlaps with a females and $\mathbf{b}$ males increased with number of sightings, regardless of sex and paired status. Filled triangles denote females and open circles males. Since number of sightings affected both sexes equally, they are represented by a joint regression line. The results were not affected by excluding encircled data points

number of sightings on the number of overlaps with females (ANCOVA: number of sightings: $\mathrm{F}_{1,86}=8.06, p=0.006$; Fig. 3a), but no significant three-way or two-way interaction between sex, paired status and number of sightings, and there was no effect of body size. One female (F173, with the largest home range) had markedly more overlaps than other individuals (Fig. 3a). Removing this female from the analysis, however, gives similar results as above (ANCOVA: sex: $\mathrm{F}_{1,85}=0.04, p=0.84$; paired status: $\mathrm{F}_{1,85}=0.73, p=0.40$; number of sightings: $\mathrm{F}_{1,85}=9.70, p=0.003$ ).

\section{Home range overlaps with males}

Unpaired females overlapped with $6.2 \pm 0.9$ males, paired females with $8.9 \pm 1.1$ males, unpaired males overlapped with $6.8 \pm 2.2$ males and paired males with $5.9 \pm 0.8$ males. There was a non-significant trend towards females having a slightly higher number of overlaps with males, but paired status had no effect (ANCOVA: sex: $\mathrm{F}_{1,86}=2.93, p=0.09$; paired status: $\left.\mathrm{F}_{1,86}<0.001, p=0.99\right)$. There was an effect of the number of sightings on the number of overlaps with males (ANCOVA: number of sightings: $\mathrm{F}_{1,86}=34.6$, $p<0.001$; Fig. 3b), but there was no significant three-way or two-way interaction between sex, paired status and number of sightings, and there was no effect of body size. Furthermore, again removing F173 from the analysis, the trend disappears (ANCOVA: sex: $\mathrm{F}_{1,85}=1.12, p=0.29$; paired status: $\mathrm{F}_{1,85}=0.78, p=0.38$; number of sightings: $\mathrm{F}_{1,85}=46.1$, $p<0.001)$.

\section{Area of overlap for mated pairs and random same-sex and opposite-sex pairs}

The results of our permutation tests show that the members of a mated pair of seahorses had home ranges that overlapped more than the home ranges of randomly chosen pairs of opposite sex individuals. The histograms for home range overlap for different categories (i.e., mated pairs, samesex individuals, or opposite-sex individuals) show that the pairwise overlap for individuals comprising a mated pair has a substantially different distribution compared to histograms of individuals that were not in a pair (Fig. 4). In particular, members of a mated pair were less likely to have no observed overlap and more likely to exhibit substantial overlap compared to seahorses that were not known to be reproducing together. Permutation tests show that this difference is significant (Fig. 5a).

A more subtle difference is also apparent in Fig. 4, which shows that randomly chosen female-female pairs had more home range overlap compared to randomly chosen malemale pairs. Even though most seahorse home ranges do not overlap, the tails of the histograms indicate that female home ranges show more overlap compared male home ranges on the rare occasions when home ranges actually do overlap (Fig. 4). Permutation tests show that this difference is highly significant (Fig. 5b).

\section{Discussion}

We have shown that female $H$. subelongatus had larger home range areas and moved greater distances than males and that the home ranges of mated pairs overlapped more with each other than with any randomly chosen individual of the opposite sex. However, we found no effect of paired status on home range size or distance moved, and no interaction between sex and paired status. Similarly, body size had no effect on home range use. All groups had home ranges that overlapped with 15-20 other individuals on average. Given that both paired and unpaired males on average overlapped 


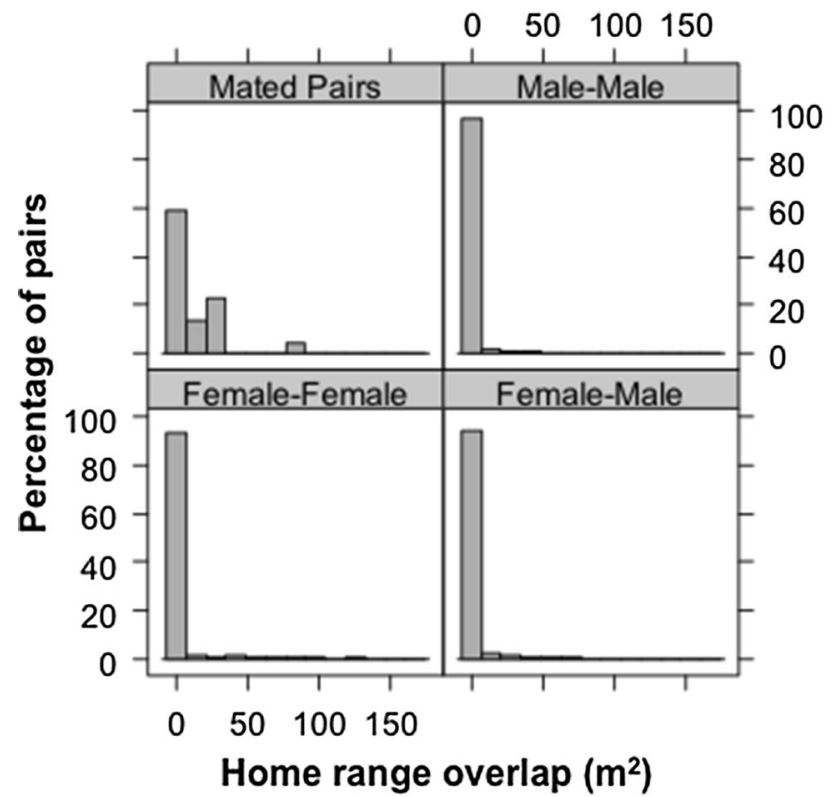

Fig. 4 Histograms showing pair-wise home range overlap for different categories of seahorse (Hippocampus subelongatus) individuals on the study site. Home rage overlap is in units of square meters. The upper left panel shows the distribution of home range overlap for male-female pairs that were known to be monogamous partners. The other three panels show results for pair-wise comparisons of all other individuals within and between the sexes (excluding known mated pairs). The home ranges of most individuals showed very little overlap, with the exception of mated pairs, who exhibit a distinctly different distribution of home range overlap (upper left panel)

with almost ten females, and paired and unpaired females overlapped with six to nine males, monogamy does not appear to be driven primarily by a lack of opportunities to find multiple individuals of the opposite sex. Below we discuss the four core questions, and then return to our predictions in the conclusions.

1. Is there a difference between home range size and distance moved between paired and unpaired males and females?

In contrast to, for example, many mammals (Clint et al. 2012), but in agreement with our expectations, we found that female $H$. subelongatus had larger home ranges and moved greater distances compared to males. These effects became most evident for individuals seen many times and were expressed as significant interactions between number of sightings and sex. These results confirm previous studies of other seahorse species (H. breviceps and $H$. whitei) that also found larger home ranges for females than for males (Moreau and Vincent 2004; Vincent et al. 2005), but differs from a study of $H$. guttulatus which found no difference in distance moved between a small number of males and

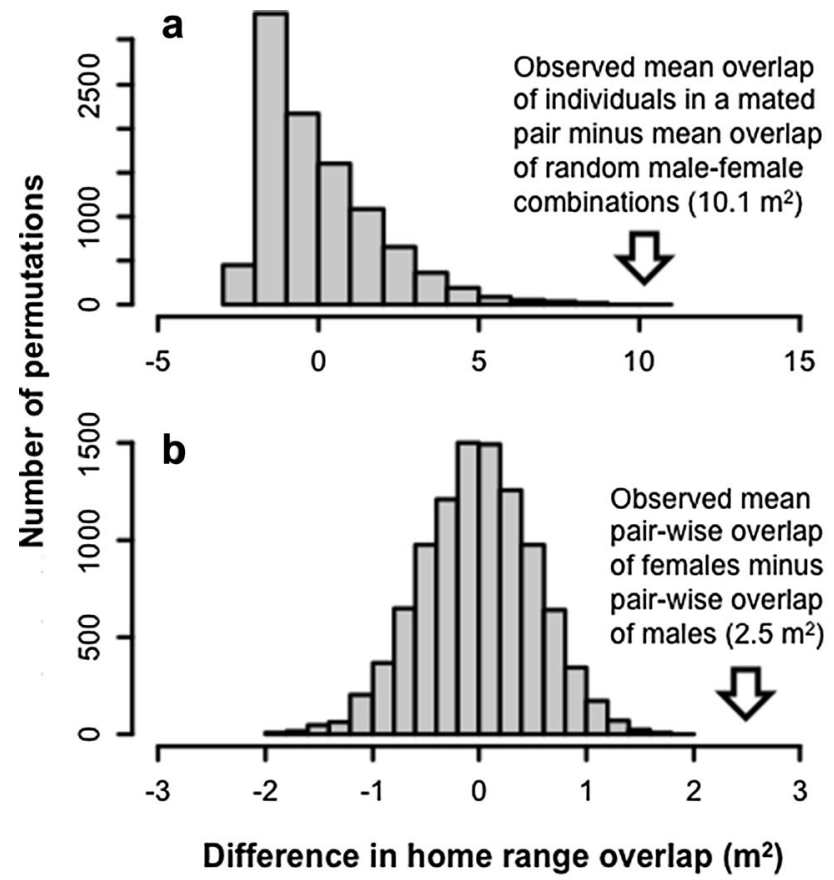

Fig. 5 Results of permutation tests comparing a home range overlap of mated seahorse pairs (Hippocampus subelongatus) to randomly chosen male-female pairs (who were not each others' mates) and $\mathbf{b}$ pair-wise overlap of female home ranges to pair-wise overlap of male home ranges. In each case, we generated a null distribution by performing 10,000 rounds of randomization of the observed values of home range overlap with respect to category of comparison (i.e. reproductive pair, randomly chosen male-female pair, etc.) and calculated the difference of interest from the randomized data. The arrow in each panel shows the observed value for the relevant comparison. Panel a shows that mated pairs have significantly more home range overlap than randomly chosen male-female combinations $(p=0.0016)$, and panel $\mathbf{b}$ shows that female home ranges exhibit significantly more pair-wise overlap than male home ranges $(p<0.0001)$

females that had been displaced from their original location (Caldwell and Vincent 2013).

We do not know if $H$. subelongatus females need more food than males or if a larger home range provides greater access to food. As ambush hunters, seahorses move less than many other fishes when they forage (Vincent et al. 2005). Still, in two species of pipefish, S. typhle and Nerophis ophidion, females invest more energy into egg production than males invest into brood rearing, despite both species showing role reversal (Berglund et al. 1986). If this result applies to other syngnathids too, egg production may put a premium on foraging for females, more so than for males, and it is possible that the larger female home ranges are explained by females being more motivated than males to move to a new site to hide and eat, if the prey density at one site drops. Nevertheless, we cannot rule out that females may be using larger home ranges for other reasons, for example competition related to access to mates. Yet, as larger females are more successful at securing a mate (Kvarnemo 
et al. 2007), one would expect home range size to correlate positively with female body size, but this was not the case. Another related possibility is that home range size relates to mate search, and consistent with this we found a strong positive correlation between home range size and the number of other individuals it overlapped with. However, since unpaired individuals did not have larger home ranges than paired ones, this explanation appears unlikely.

Two females had strikingly larger home ranges than others. Removing them from the analysis did not change the result that females had larger home ranges than males, when controlling for number of sightings. Why did these two have such large home ranges? It seems the reasons differ. The first female (F173) was relatively large (head length $39.0 \mathrm{~mm}$; cf. Figure 2 in Kvarnemo et al. 2007), and paired to a medium sized male (M125; head length $33.5 \mathrm{~mm}$ ). M125 was seen twice, early in the study (Jan 21 and Feb 5: pregnant both times), around the stumps at the eastern end of the demolished jetty, and F173 was seen nine times, the first seven of these (Feb 8-23) in the same small area as M125. However, after that F173 suddenly moved $78 \mathrm{~m}$ to the area around the jetty pylons (Mar 1 and Mar 11). This is the longest move recorded between two consecutive sightings in this study, and clearly above the average distance moved $(6.4 \mathrm{~m})$. One possible interpretation of why F173 relocated from one part of the study area to another at that point in time, is that M125 had disappeared from the study area (for unknown reasons). It is possible that F173 waited for 2-3 weeks (approximate brood time) after M125 was last seen, and then she moved on in search of a new mate. This behavior of F173 resembles what has previously been documented for $H$. subelongatus males, namely that males who switched mates between two successive broods moved greater distances and tended to have longer inter-brood intervals, compared to males that bred with the same female (Kvarnemo et al. 2000). Similarly, in $H$. whitei males that lost a mate would relocate to a new home range within the reef before mating with a new female (Vincent et al. 2005). The second female (F223) with an unusually large home range was small (head length $30.0 \mathrm{~mm}$ ) and apparently unpaired. This female was seen eight times, all around the stumps of the demolished jetty, where she moved consistently around the area. Given her small body size, and hence relatively low chance of securing a mate (Kvarnemo et al. 2007), it is more likely she was foraging than actively looking for a mate.

We also removed four data points belonging to three males and one female that were known to have switched partners between broods, as previous work on both $H$. subelongatus and $H$. whitei (Kvarnemo et al. 2000; Vincent et al. 2005) suggest that breeding with a new partner is associated with a shift in home ranges, at least for males. However, the movements of these four individuals did not exceed that of others seen the same numbers of times, and hence removing them did not affect our results. It is however interesting to note that one of the males (M204, seen 4 times) did not move at all, despite partner change.

Based on data from the same individual seahorses, but analyzed differently, Kvarnemo et al. (2007) found that paired males were seen at fewer different sites (pylons or stumps), indicating they had smaller home ranges and moved around less than unpaired males, and paired and unpaired females. This result was only partly confirmed in this study, as males had smaller home ranges and moved less than females, but no significant difference between paired and unpaired males was found, when home range use was measured as distance moved or area, rather than number of sites seen as in Kvarnemo et al. (2007). Another difference from the previous study is that all individuals with a single sighting were excluded from the present dataset. There was also a difference in models used (one factor with four levels, instead of two factors with two levels each in the current study). However, as shown in Tables S1 and S2 in Online Resource 1, sample size had surprisingly little effect on the outcome, whereas choice of ANCOVA model and method to estimate home range size had some impact. Overall however, based on Table S2, the results presented in the current study appear to be robust, namely that there is a significant effect of sex on home range size, expressed as a significant interaction between sex and number of sightings, but no effect of paired status on home range size.

2. Home range overlap measured as number of individuals: Do the home ranges of unpaired males or females overlap with a larger number of opposite sex individuals than paired individuals do?

Unpaired males did not overlap with more females, which suggests they were not more active in mate search than other groups. Given that there was a female biased adult sex ratio, unpaired males may not have needed to search far for females, which may explain why they did not overlap with more females. In addition, the lack of effect of sex and paired status can partly be due to the low number of males that remained unpaired. With 1.4 females per male in the study area, it is intriguing that any adult males remained unpaired, as this should have provided ample mating opportunities. One explanation as to why some males remained unpaired is choosiness by both sexes, as found in both $H$. abdominalis and H. guttulatus (Bahr et al. 2012; Faleiro et al. 2016). Another possible explanation might be that 'unpaired' males had a temporary break from breeding when sighted, and thus were incorrectly categorized as unpaired.

With a female biased adult sex ratio and a large proportion of unpaired females in the study area, we would have predicted unpaired females to be more active and to overlap with more males compared to paired females, and 
paired and unpaired males. However, our results do not support this prediction. Although females moved more and had larger home ranges than males, and we found a weak non-significant trend suggesting that females encountered slightly more males, paired status did not have an impact on this. Thus, unpaired females did not move further or overlap with more males than paired females did. This lack of difference between the paired and unpaired females may, to some extent, be explained by the uncertainty in our estimates of female paired status, but it may also mean our prediction was incorrect.

3. Home range overlap measured as area: Do mated pairs overlap more than other opposite sex individuals and do male-male and female-female overlaps differ in extent?

The home ranges of most seahorses in this study showed very little overlap, with one exception. Mated pairs had fewer overlaps of zero square meters and the mean overlapping home range area was significantly greater than the mean overlapping area for randomly chosen pairs of opposite sex individuals. This result confirms our prediction that mated pairs do overlap spatially to a greater extent than other individuals. It also shows that if genetically based information on paired status is lacking or uncertain, home range overlap could be used to predict or confirm whether two individuals are likely to be in a pair-bond or not.

Comparing female-female overlaps to male-male overlaps, we found more cases of large home range overlaps among females. This result is probably due to the female biased adult sex ratio in the study population, and to females in general having larger home ranges, although it might also mean that females seek out each other, or at the very least, that they do not actively avoid each other.

\section{Is home range use affected by body size?}

Consistent with results for $H$. whitei and $H$. guttulatus (Vincent et al. 2005; Curtis and Vincent 2006), we found no effect of body size on home range use of either sex. This is contrary to our prediction, which was based on results from the pipefish S. typhle, in which adults of both males and females were more interested in food when they were small and in mates when they were larger (Berglund et al. 2006). This might mean that $H$. subelongatus does not change interest in the same way as $S$. typhle as they grow larger, or perhaps that it does not translate to an altered home range use. We also surmised that especially larger females might have smaller home ranges, since they would be more likely to be paired (Kvarnemo et al. 2007) and hence should be in less need to move around in search of a mate, or alternatively that larger females should have larger home ranges, if home range size is positively correlated to mating success. However, neither of these predictions was supported by our observations. Apparently home range use is not affected by body size in either sex in $H$. subelongatus. Still, our study only covered the second half of the breeding season. Thus, we may have found effects of body size if we had been able to follow the individuals from the start.

\section{Is low mate availability a likely explanation for sequen- tial monogamy in the study population?}

Herold and Clark (1993) argued that monogamous mating behavior found in the seamoth Eurypegasus draconis could be explained by low mobility and small home ranges restricting their chances of finding alternative mates. If the same is true in $H$. subelongatus, which also shows monogamy, low mobility and small home ranges, we expected little overlap with opposite sex individuals. However, we found that, on average, paired and unpaired males overlapped with 10.0 and 9.8 females, and paired and unpaired males overlapped with 6.2 and 8.8 females, respectively. This suggests that their monogamous mating behavior is not driven by a marked lack of opportunity to find other individuals of the opposite sex.

\section{Conclusions}

Our results suggest that home range use in $H$. subelongatus is mainly affected by sex and by the partner's home range. We found that females had larger home ranges and moved greater distances than males, indicating that they use a larger area, possibly to forage more efficiently. However, we found no indication that unpaired individuals would move around more than paired ones in search of mates or overlap more in extent or number of individuals of the opposite sex. Thus, contrary to our prediction, paired status had no significant effect on home range use, but we found that mated pairs had home ranges that overlapped more extensively than those of randomly chosen pairs of males and females. We found no effect of body size on home range use, thus showing no support for our predictions related to body size. In addition, we found that female home ranges overlapped more with one another than male home ranges did. We had no a priori prediction regarding this result, but we interpret it as resulting from females having larger home ranges combined with the female biased adult sex ratio in the studied population. Finally, despite their small home ranges and low mobility, we found that both sexes had home ranges that overlapped with relatively large numbers of individuals, suggesting that their monogamous mating pattern is not governed by a lack of opportunity to mate with other individuals of the opposite sex. This is important in a wider context, since the evolution 
of monogamous mating behavior has been suggested to be driven by low mobility and small home ranges restricting access to alternative mates (Barlow 1984; Whiteman and Côté 2004; Kokko and Rankin 2006).

Acknowledgements We thank the Department of Zoology at the University of Western Australia for SCUBA equipment, Anna Karlsson for field assistance, DeEtte Walker and John Avise for help with microsatellite analysis, Mikael Landin for initial analysis of home range sizes, and Karoline Fritzsche, Jonathan Henshaw and Bernadette Johnson for comments on the manuscript.

Author contributions Charlotta Kvarnemo, Glenn Moore and Adam Jones, contributed to the conception and design of the study. Data collection in the field was performed by Charlotta Kvarnemo and Glenn Moore, parentage analysis to establish pair bonds was done by Adam Jones. All home range data were extracted and analyzed by Susanne Andersson, Jonas Elisson wrote the code in Python, Adam Jones wrote the code in $\mathrm{R}$ and carried out the permutation tests. The first drafts of the manuscript were written by Susanne Andersson and Charlotta Kvarnemo and all authors contributed to previous versions of the manuscript. All authors read and approved the final manuscript.

Funding Open access funding provided by University of Gothenburg. This work was supported by the Swedish Research Council (B1187/1999; 621-2005-4925) and Magn. Bergvall Foundation to Charlotta Kvarnemo, by the Department of Zoology at the University of Western Australia to Glenn I. Moore, and by the National Science Foundation (DEB-9804247) to Adam G. Jones.

Availability of data and material https://doi.org/10.5061/dryad.w9ghx 3fnz.

\section{Declarations}

Conflict of interest The authors declare that they have no conflict of interest.

Ethics approval This research was approved by the Department of Fisheries in Western Australia and the Animal Ethics Committee at the University of Western Australia (Approval No. 76/95/95). All applicable international, national, and/or institutional guidelines for the use of animals were followed.

Consent to participate All authors have given their consent.

Consent for publication All authors have given their consent.

Significance statement Animal space use over time often reflects important decisions related to feeding and breeding. The West Australian seahorse does not defend territories, but keeps home ranges. Males and females keep separate home ranges, despite forming monogamous pair-bonds. We found that, although females had larger home ranges and moved greater distances than males, home ranges of reproducing pairs overlapped more with one another than with randomly chosen individuals of either sex. Both sexes, whether paired or unpaired, had home ranges that overlapped with home ranges of 6-10 opposite-sex individuals on average. Consequently, a lack of access to available mates is unlikely to be the main factor underlying monogamy in this species. Contrary to our expectation, unpaired seahorses did not move around more than paired ones. We also found no effect of body size on home-range size, distance moved or home-range overlap.
Open Access This article is licensed under a Creative Commons Attribution 4.0 International License, which permits use, sharing, adaptation, distribution and reproduction in any medium or format, as long as you give appropriate credit to the original author(s) and the source, provide a link to the Creative Commons licence, and indicate if changes were made. The images or other third party material in this article are included in the article's Creative Commons licence, unless indicated otherwise in a credit line to the material. If material is not included in the article's Creative Commons licence and your intended use is not permitted by statutory regulation or exceeds the permitted use, you will need to obtain permission directly from the copyright holder. To view a copy of this licence, visit http://creativecommons.org/licenses/by/4.0/.

\section{References}

Avise JC (1996) Three fundamental contributions of molecular genetics to avian ecology and evolution. Ibis 138:16-25

Bahr A, Sommer S, Mattle B, Wilson AB (2012) Mutual mate choice in the potbellied seahorse (Hippocampus abdominalis). Behav Ecol 23:869-878. https://doi.org/10.1093/beheco/ars045

Barlow GW (1984) Patterns of monogamy among teleost fishes. Arch FischWiss 35:75-123

Berglund A, Rosenqvist G, Svensson I (1986) Reversed sex roles and parental energy investment in zygotes of two pipefish (Syngnathidae) species. Mar Ecol Prog Ser 29:209-215

Berglund A, Rosenqvist G, Robinson-Wolrath S (2006) Food or sexmales and females in a sex role reversed pipefish have different interests. Behav Ecol Sociobiol 60:281-287. https://doi.org/10. 1007/s00265-006-0166-4

Boyle SA, Lourenço WC, da Silva LR, Smith AT (2009) Home range estimates vary with sample size and methods. Folia Primatol 80:33-42. https://doi.org/10.1159/000201092

Brotherton PNM, Pemberton JM, Komers PE, Malarky G (1997) Genetic and behavioural evidence of monogamy in a mammal, Kirk's dik-dik (Madoqua kirkii). Proc R Soc Lond B 264:675-681

Brown GP, Weatherhead PJ (1999) Female distribution affects mate searching and sexual selection in male northern water snakes (Nerodia sipedon). Behav Ecol Sociobiol 47:9-16

Burt WH (1943) Territoriality and home range concepts as applied to mammals. J Mammal 24:346-352

Caldwell IR, Vincent ACJ (2013) A sedentary fish on the move: effects of displacement on long-snouted seahorse (Hippocampus guttulatus Cuvier) movement and habitat use. Environ Biol Fish 96:67-75. https://doi.org/10.1007/s10641-012-0023-4

Clint EK, Sober E, Garland T Jr, Phodes JS (2012) Male superiority in spatial navigation: Adaptation or side effect? Q Rev Biol 87:289-313. https://doi.org/10.1086/668168

Clutton-Brock TH (1989) Mammalian mating systems. Proc R Soc Lond B 236:339-372. https://doi.org/10.1098/rspb.1989.0027

Curtis JMR, Vincent AJC (2006) Life history of an unusual marine fish: survival, growth and movement patterns of Hippocampus guttulatus Cuvier 1829. J Fish Biol 68:707-733. https://doi.org/ 10.1111/j.1095-8649.2006.00952.x

DeWoody JA, Avise JC (2001) Genetic perspectives on the natural history of fish mating systems. J Hered 92:167-172

DeWoody JA, Fletcher DE, Wilkins SD, Nelson WS, Avise JC (2000) Genetic monogamy and biparental care in an externally fertilizing fish, the largemouth bass (Micropterus salmoides). Proc R Soc Lond B 267:2431-2437

Egger B, Obermüller B, Phiri H, Sturmbauer C, Sefc KM (2006) Monogamy in the maternally mouthbrooding Lake Tanganyika cichlid fish Tropheus moorii. Proc R Soc B 273:1797-1802 
Emlen ST, Oring LW (1977) Ecology, sexual selection, and the evolution of mating systems. Science 197:215-223

Faleiro F, Almeida AJ, Ré P, Narciso L (2016) Size does matter: An assessment of reproductive potential in seahorses. Anim Reprod Sci 170:61-67. https://doi.org/10.1016/j.anireprosci.2016.04.003

Foley AM, DeYoung RW, Hewitt DG, Hellickson MW, Gee KL, Wester DB, Lockwood MA, Miller KV (2015) Purposeful wanderings: mate search strategies of male white-tailed deer. J Mammal 96:279-286. https://doi.org/10.1093/jmammal/gyv004

Garcia AM, Geraldi RM, Vieira JP (2005) Diet composition and feeding strategy of the southern pipefish Syngnathus folletti in a Widgeon grass bed of the Patos Lagoon Estuary, RS, Brazil. Neotrop Ichthyol 3:427-432. https://doi.org/10.1590/S1679-6225200500 0300011

Griffith SC, Owens IPF, Thuman KA (2002) Extra pair paternity in birds: a review of interspecific variation and adaptive function. Mol Ecol 11:2195-2212

Harris S, Cresswell WJ, Forde PG, Trewhella WJ, Woollard T, Wray S (1990) Home-range analysis using radio-tracking data - a review of problems and techniques particularly as applied to the study of mammals. Mammal Rev 20:97-123. https://doi.org/10.1111/j. 1365-2907.1990.tb00106.x

Herald ES (1959) From pipefish to seahorse - a study of phylogenetic relationships. Proc Calif Acad Sci 29:465-473

Herold D, Clark E (1993) Monogamy, spawning and skin-shedding of the sea moth, Eurypegasus draconis (Pisces: Pegasidae). Environ Biol Fish 37:219-236

Hixon MA (1987) Territory area as a determinant of mating systems. Am Zool 27:229-247

Hohoff C, Solmsdorff K, Lottker P, Kemme K, Epplen JT, Cooper TG, Sachser N (2002) Monogamy in a new species of wild guinea pig (Galea sp.). Naturwissensch 89:462-465

Huck M, Fernandez-Duque E, Babb P, Schurr T (2014) Correlates of genetic monogamy in socially monogamous mammals: insights from Azara's owl monkeys. Proc R Soc B 281:20140195. https:// doi.org/10.1098/rspb.2014.0195

Janicke T, David P, Elodie Chapuis E (2015) Environment-dependent sexual selection: Bateman's parameters under varying levels of food availability. Am Nat 185:756-768. https://doi.org/10.1086/ 681128

Jones AG, Kvarnemo C, Moore GI, Simmons LW, Avise JC (1998) Microsatellite evidence for monogamy and sex-biased recombination in the Western Australian seahorse Hippocampus angustus. Mol Ecol 7:1497-1506. https://doi.org/10.1046/j.1365-294x. 1998.00481.x

Jones AG, Moore GI, Kvarnemo C, Walker D, Avise JC (2003) Sympatric speciation as a consequence of male pregnancy in seahorses. Proc Natl Acad Sci USA 100:6598-6603. https://doi.org/10.1073/ pnas. 1131969100

Kelt DA, Van Vuren D (1999) Energetic constraints and the relationship between body size and home range area in mammals. Ecology 80:337-340

Kitsos MS, Tzomos T, Anagnostopoulou L, Koukouras A (2008) Diet composition of the seahorses, Hippocampus guttulatus Cuvier, 1829 and Hippocampus hippocampus (L., 1758) (Teleostei, Syngnathidae) in the Aegean Sea. J Fish Biol 72:1259-1267. https:// doi.org/10.1111/j.1095-8649.2007.01789.x

Kleven O, Bjerke B-A, Lifjeld JT (2008) Genetic monogamy in the common crossbill (Loxia curvirostra). J Ornithol 149:651-654. https://doi.org/10.1007/s10336-008-0291-0

Kokko H, Rankin DJ (2006) Lonely hearts or sex in the city? Density-dependent effects in mating systems. Phil Trans R Soc B 361:319-334

Kvarnemo C (1997) Food affects the potential reproductive rates of sand goby females but not of males. Behav Ecol 8:605-611. https://doi.org/10.1093/beheco/8.6.605
Kvarnemo C (2018) Why do some animals mate with one partner rather than many? A review of causes and consequences of monogamy. Biol Rev 93:1795-1812. https://doi.org/10.1111/brv.12421

Kvarnemo C, Jones AG, Moore GI, Hensman W, Avise JC (2000) Monogamous pair bonds and mate switching in the Western Australian seahorse Hippocampus subelongatus. J Evol Biol 13:882888. https://doi.org/10.1046/j.1420-9101.2000.00228.x

Kvarnemo C, Moore GI, Jones AG (2007) Sexually selected females in the monogamous Western Australian seahorse Hippocampus subelongatus. Proc R Soc B 274:521-525. https://doi.org/10.1098/ rspb.2006.3753

Lourie SA, Vincent ACJ, Hall HJ (1999) Seahorses: an identification guide to the world's species and their conservation. Project Seahorse, London

Lyons DO, Dunne JJ (2004) Inter- and intra-gender analyses of feeding ecology of the worm pipefish (Nerophis lumbriciformis). J Mar Biol Assoc UK 84:461-464. https://doi.org/10.1017/S0025 315404009452h

Manning CG, Foster SJ, Vincent ACJ (2019) A review of the diets and feeding behaviours of a family of biologically diverse marine fishes (Family Syngnathidae). Rev Fish Biol Fisheries 29:197221. https://doi.org/10.1007/s11160-019-09549-z

Marks JS, Dickinson JL, Haydock J (1999) Genetic monogamy in longeared owls. Condor 101:854-859

Masonjones HD, Lewis SM (2000) Differences in potential reproductive rates of male and female seahorses related to courtship roles. Anim Behav 59:11-20

Miller CW, Svensson EI (2014) Sexual selection in complex environments. Annu Rev Entomol 59:427-445. https://doi.org/10.1146/ annurev-ento-011613-162044

Moreau M-A, Vincent ACJ (2004) Social structure and space use in a wild population of the Australian short-headed Hippocampus breviceps Peters, 1869. Mar Freshw Res 55:231-239. https://doi. org/10.1071/MF03159

Piper WH, Evers DC, Meyer MW, Tischler KB, Kaplan JD, Fleischer RC (1997) Genetic monogamy in the common loon. Behav Ecol Sociobiol 41:25-31

Radespiel U (2000) Sociality in the gray mouse lemur (Microcebus murinus) in northwestern Madagascar. Am J Primatol 51:21-40

Ribble DO (1991) The monogamous mating system of Peromyscus californicus as revealed by DNA fingerprinting. Behav Ecol Sociobiol 29:161-166

Robertson BC, Degnan SM, Kikkawa J, Moritz CC (2001) Genetic monogamy in the absence of paternity guards: the Capricorn silvereye, Zosterops lateralis chlorocephalus, on Heron Island. Behav Ecol 12:666-673

Rodriguez-Martínez S, Carrete M, Roques S, Rebolo-Ifrán N, Tella JL (2014) High urban breeding densities do not disrupt genetic monogamy in a bird species. PLoS ONE 9:e91314. https://doi.org/ 10.1371/journal.pone.0091314

Rose E, Small CM, Saucedo HA, Harper C, Jones AG (2014) Genetic evidence for monogamy in the dwarf seahorse, Hippocampus zosterae. J Hered 105:922-927. https://doi.org/10.1093/jhered/ esu050

Schaedelin FC, van Dongen WFD, Wagner RH (2015) Mate choice and genetic monogamy in a biparental, colonial fish. Behav Ecol 26:782-788. https://doi.org/10.1093/beheco/arv011

Seaman DE, Millspaugh JJ, Kernohan BJ, Brundige GC, Raedeke KJ, Gitzen RA (1999) Effects of sample size on kernel home range estimates. J Wildl Manage 63:739-747

Steffe AS, Westoby M, Bell JD (1989) Habitat selection and diet in two species of pipefish from seagrass: sex differences. Mar Ecol Prog Ser 55:23-30. https://doi.org/10.3354/meps055023

Stölting KN, Wilson AB (2007) Male pregnancy in seahorses and pipefish: beyond the mammalian model. BioEssays 29:884-896. https://doi.org/10.1002/bies.20626 
Svensson I (1988) Reproductive costs in two sex-role reversed pipefish species (Syngnathidae). J Anim Ecol 57:929-942

Syrůčková, A, Saveljev, AP, Frosch, C, Durka, W, Savelyev, AA, Munclinger, P, (2015) Genetic relationships within colonies suggest genetic monogamy in the Eurasian beaver (Castor fiber). Mamm Res 60:139-147. https://doi.org/10.1007/s13364-015-0219-z

Tamburello N, Côté IM, Dulvy NK (2015) Energy and the scaling of animal space use. Am Nat 186:196-211. https://doi.org/10.1086/ 682070

Tatarenkov A, Barreto F, Winkelman DL, Avise JC (2006) Genetic monogamy in the channel catfish, Ictalurus punctatus, a species with uniparental nest guarding. Copeia 2006:735-741

Teixeira RL, Musick JA (1995) Trophic ecology of two congeneric pipefishes (Syngnathidae) of the lower York River, Virginia. Environ Biol Fish 43:295-309. https://doi.org/10.1007/BF00005862

Vincent ACJ (1994) Operational sex ratios in seahorses. Behaviour 128:153-167

Vincent AJC, Sadler LM (1995) Faithful pair bonds in wild seahorses, Hippocampus whitei. Anim Behav 50:1557-1569

Vincent ACJ, Marsden AD, Evans KL, Sadler LM (2004) Temporal and spatial opportunities for polygamy in a monogamous seahorse, Hippocampus whitei. Behaviour 141:141-156

Vincent ACJ, Evans KL, Marsden AD (2005) Home range behaviour of the monogamous Australian seahorse, Hippocampus whitei. Environ Biol Fish 72:1-12

Whiteman EA, Côté IM (2004) Monogamy in marine fishes. Biol Rev 79:351-375
Whittington CM, Friesen CR (2020) The evolution and physiology of male pregnancy in syngnathid fishes. Biol Rev. https://doi.org/ $10.1111 /$ brv. 12607

Wilson AB, Martin-Smith KM (2007) Genetic monogamy despite social promiscuity in the pot-bellied seahorse (Hippocampus abdominalis). Mol Ecol 16:2345-2352. https://doi.org/10.1111/j. 1365-294X.2007.03243.x

Wilson AB, Vincent A, Ahnesjö I, Meyer A (2001) Male pregnancy in seahorses and pipefishes (Family Syngnathidae): Rapid diversification of paternal brood pouch morphology inferred from a molecular phylogeny. J Hered 92:159-166

Woodall LC, Koldewey HJ, Shaw PW (2011) Serial monogamy in the European long-snouted seahorse Hippocampus guttulatus. Conserv Genet 12:1645-1649. https://doi.org/10.1007/ s10592-011-0253-6

Worton BJ (1987) A review of models of home range for animal movement. Ecol Model 38:277-298. https://doi.org/10.1016/03043800(87)90101-3

Publisher's Note Springer Nature remains neutral with regard to jurisdictional claims in published maps and institutional affiliations. 